\title{
Ponto de cultura: a construção de uma política pública
}

Célio Turino

O artigo descreve iniciativas culturais organizadas e mantidas por grupos sociais locais contemplados, por meio de editais, com recursos públicos do Programa Cultura Viva, do Ministério da Cultura. A descrição é permeada por uma análise a respeito dos pressupostos teóricos que fundamentaram o Programa, bem como das características que garantiram a sobrevivência das iniciativas populares financiadas. Partindo da análise empírica de casos, o autor argumenta que iniciativas culturais autônomas - oriundas de demandas comunitárias - e que apostam no protagonismo social das pessoas envolvidas têm maiores chances de êxito, cabendo ao poder público potencializá-las de modo a promover o empoderamento dos sujeitos sociais. Conclui que as experiências dos Pontos de Cultura oferecem novos matizes para a aproximação entre estética, ética e economia.

Palavras-chave: Programa Cultura Viva; Pontos de Cultura; políticas culturais; políticas públicas 


\section{Culture point: the construction of a}

public policy

Célio Turino

The article describes some cultural initiatives organized and maintained by local social groups contemplated, by bidding notices, with public funds from Cultura Viva Program, of the Ministry of Culture. The description is permeated by an analysis on the theoretical assumptions that founded the Program, as well as the characteristics that assured the survival of the popular initiatives funded. Starting from an empirical analysis of cases, the author claims that autonomous cultural initiatives - originating from community demands - and that bet on the social protagonism of those involved have higher chances of success, and it is up to the public authorities to potentiate them so as to promote the empowering of social subjects. It is concluded that the experiences of Culture Points offer new nuances for the approximation between aesthetic, ethic and economy.

key words: Cultura Viva Program; Culture Points; cultural policies; public policies 
1 . S I TI

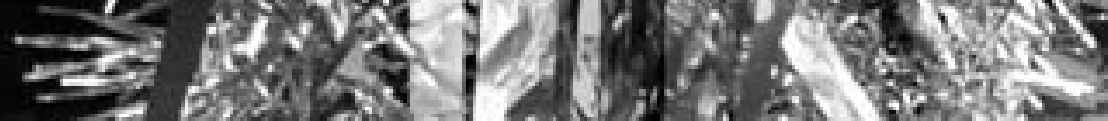
CBys

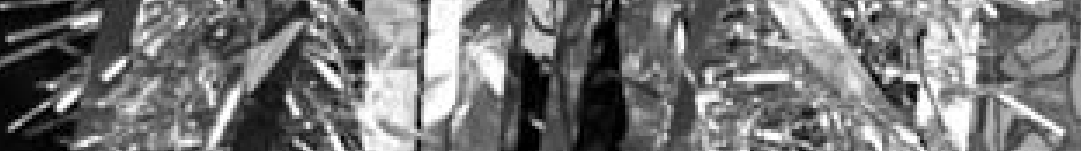

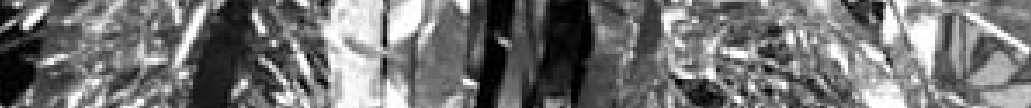
3 in a d E 301. a gowis 7 mas rignis i.

1 a)
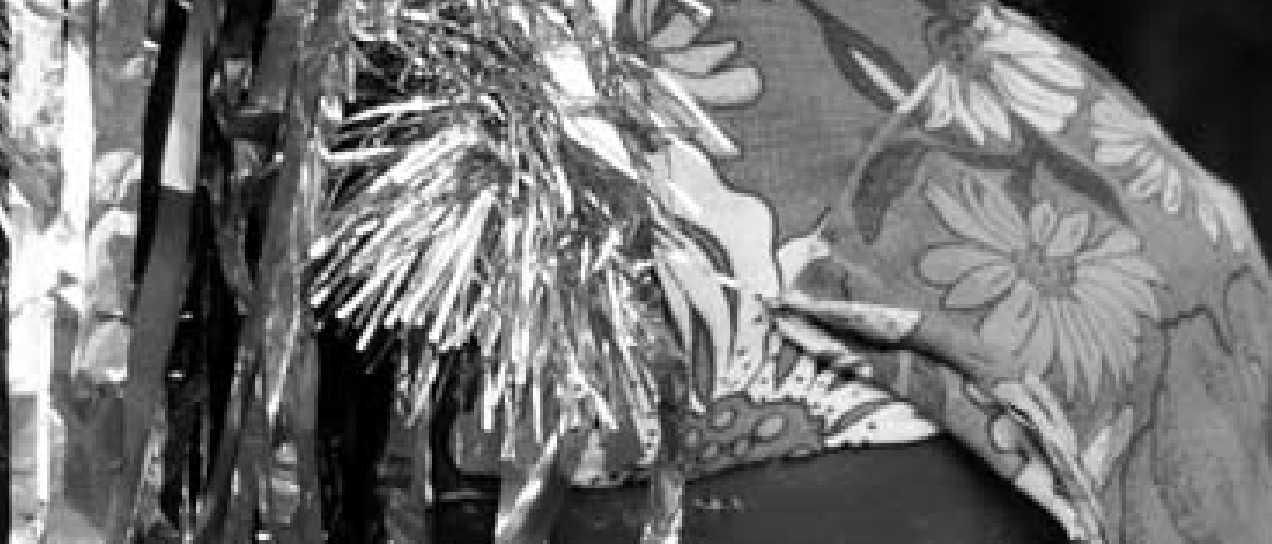

Q.

is: ,

pis

(3.). की

siogte<smiles>C1CC2CC3CC(C3)C(C1)C2</smiles>

1. (1)

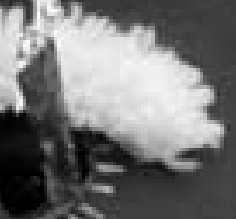

$y^{1}=-2$

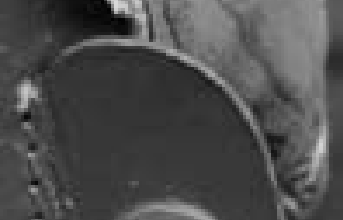

int

14

4

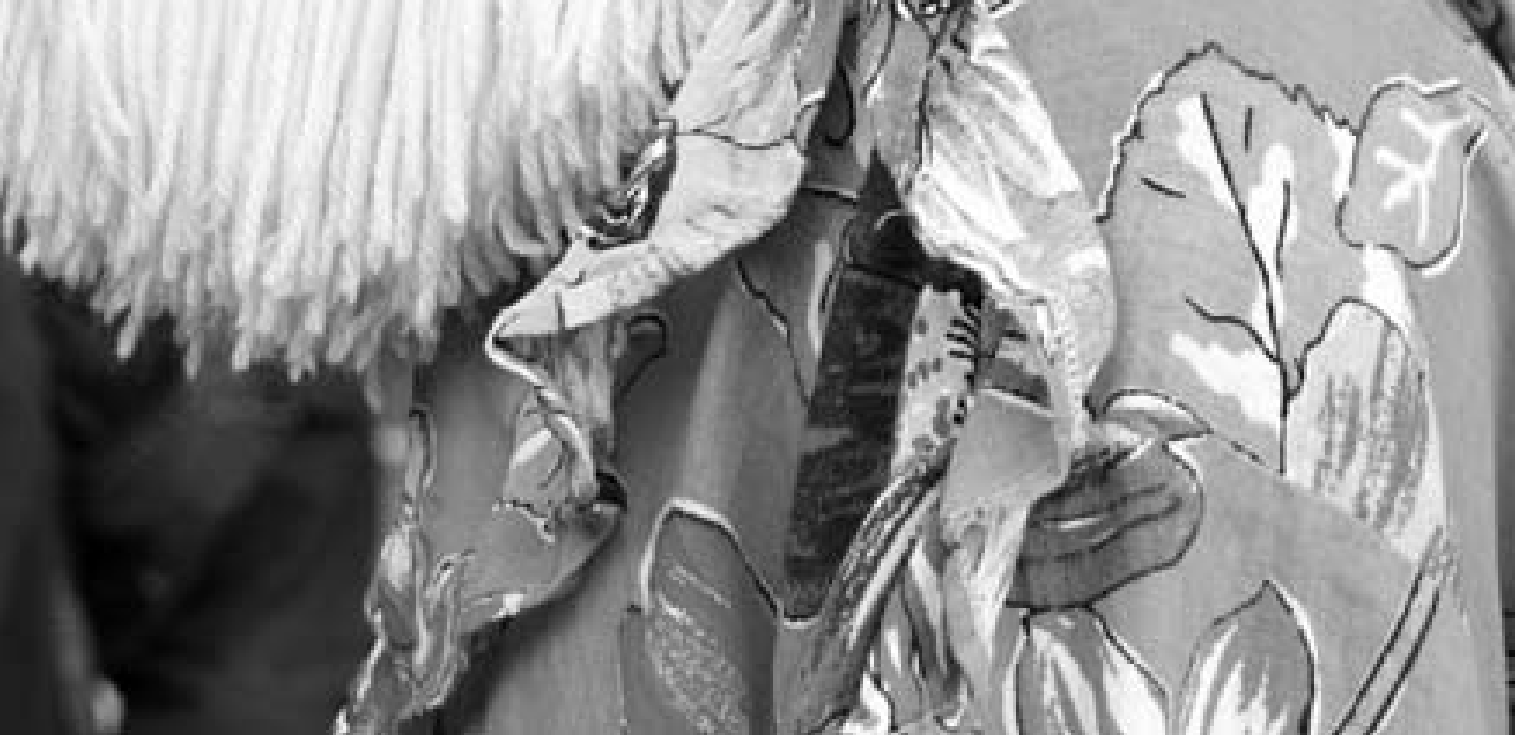




\section{Ponto de Cultura: a construção de uma política} ceno тureno * pública.

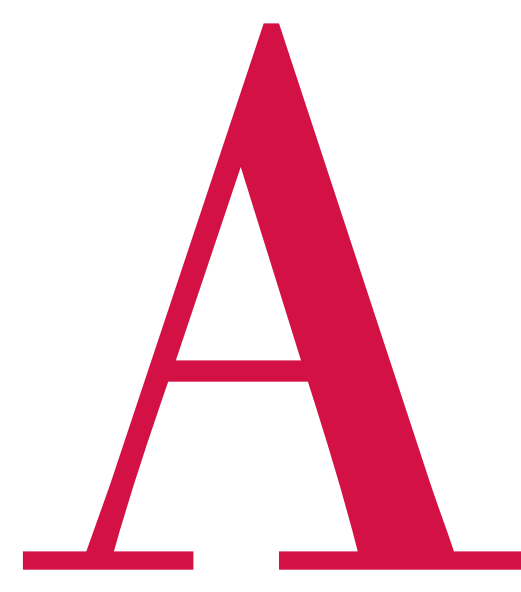

Um novo estado se forma quando ouvimos quem nunca foi ouvido

aplicação do conceito de gestão compartilhada e transformadora para os Pontos de Cultura tem por objetivo estabelecer novos parâmetros de gestão e democracia entre estado e sociedade. No lugar de impor uma programação cultural ou chamar os grupos culturais para dizerem o que querem (ou necessitam), perguntamos como querem. Em vez de entender a cultura como produto, ela é reconhecida como processo.

Esse novo conceito se expressou com o edital de 2004, para seleção dos primeiros Pontos de Cultura. Invertemos a forma de abordagem dos grupos sociais e 0 Ministério da Cultura disse quanto podia oferecer e os proponentes definiam, a partir de seu ponto de vista e de suas necessidades, como aplicariam os recursos.

Em algumas propostas, o investimento maior vai para a adequação física do espaço; em outras, para a compra de equipamentos ou, como na maioria, para a realização de oficinas e atividades continuadas. 0 único elemento comum a todos é o estúdio multimídia, que permite gravar músicas, produzir audiovisuais e colocar toda a produção na internet.

* CÉlıo Turino, historiador e administrador de cultura e lazer, é secretário de Cidadania Cultural do Ministério da Cultura - MinC. 
Ponto de Cultura é um conceito de política pública. São organizações culturais da sociedade que ganham força e reconhecimento institucional ao estabelecer uma parceria, um pacto, com o Estado. Aqui há uma sutil distinção: o Ponto de Cultura não pode ser para as pessoas, e sim das pessoas; deve constituir-se em organizador da cultura no nível local, atuando como um ponto de recepção e irradiação de cultura.

Como um elo na articulação em rede, o Ponto de Cultura não é um equipamento cultural do governo nem um serviço. Seu foco não está na carência, na ausência de bens e serviços, e sim na potência, na capacidade de agir de pessoas e grupos. Ponto de Cultura é cultura em processo, desenvolvida com autonomia e protagonismo social.

A gestão do Ponto de Cultura começa a partir do convênio que é assinado entre governo e proponentes, definindo:

- responsabilidades - acesso público ao Ponto, trabaIho colaborativo, compartilhamento de decisões com a comunidade; e

- direitos - regularidade no repasse de recursos, acompanhamento e capacitação, acesso público aos bens e serviços adquiridos com os recursos repassados etc.

Como o Ponto continua desenvolvendo suas atividades, independente do convênio, a dinâmica de cada organização precisa ser respeitada. Alguns são ONGs voltadas para a ação socioeducativa; outros, escolas de samba, associações de moradores, quilombolas, aldeias indígenas, grupos de teatro, conservatórios, núcleos de extensão universitária, museus, cooperativas de assentamentos rurais. Cada qual com sua especificidade e forma de organização.

Durante o processo de implantação e acompanhamento dos Pontos, há tensão. De um lado, os grupos culturais, apropriando-se de mecanismos de gestão e recursos públicos; de outro, o Estado, com normas de controle e regras rígidas. Essa tensão, de certo modo inevitável, cumpre um papel educativo que, no longo prazo, resultará em mudanças em ambos os campos. 0 objetivo seria uma burocracia mais flexível e adequada à realidade da vida, assim como um movimento social mais bem preparado no trato das questões de gestão, capacitando-se para melhor acompanhar as políticas públicas e o planejamento de suas atividades específicas.

Essa interação, que no início é difícil, exige o exercício de um novo modelo de estado, diferente dos até então conhecidos. Nos padrões conhecidos, temos de optar por formas pesadas de estado, de caráter intervencionista e burocrático, ou então o estado mínimo, com sensibilidade às necessidades sociais igualmente mínima. Um estado de "novo tipo", que compartilha poder com novos sujeitos sociais, ouve quem nunca foi ouvido, conversa com quem nunca conversou, vê os invisíveis. Por isso torna-se ampliado, presente e ao mesmo tempo leve como o ar.

\footnotetext{
Nós, o povo do santo, aqui em Pernambuco, estamos com a autoestima levantada (...). Os terreiros de candomblé sempre foram tratados com intolerância. Quantas vezes fomos saqueados pela polícia, que tirava todos os nossos fundamentos! No porão do Palácio do Campo das Princesas [sede do governo do estado] estão jogados, feito pó, todos os nossos fundamentos, os ibás [arranjos em cerâmica e panelas para oferendas], os ilu [instrumentos musicais, atabaques], os assentamentos [pedras]. Agora, quando a polícia aparece, nós dizemos:

- 0 que vocês querem? Somos Ponto de Cultura, reconhecidos pelo governo federal.

E a zabumba, que foi dos nossos avós e tem mais de 150 anos, pode tocar a sambada, a ciranda, o samba de coco, o maracatu e todos os encontros de brincantes.
}

Beth de Oxum

Ponto de Cultura Memória e Produção da Cultura Popular Coco de Umbigada, Olinda, Pernambuco.

Há risco de, nesse processo, os movimentos culturais irem se institucionalizando, perderem a espontaneidade ou até mesmo serem cooptados? Há.

Diante dessa perspectiva, a cultura política e o elemento de emancipação surgem como fundamentais para evitar esse processo de cooptação. Aqui, entenda-se por cooptação a contaminação do "mundo da vida" (cultura, sociedade, pessoa) pelo "mundo dos sistemas" (estado, mercado).

Em contraponto, precisamos encorajar uma ação que desenvolva e fortaleça competências do sujeito (coletivo e individual), o reencontro com as pessoas e a sua capacidade de agir enquanto agentes históricos.

Assim, ampliando a capacidade de interpretação do mundo, reequilibrando ordens legítimas que regulamentem a relação entre grupos sociais e garantam a solidariedade entre eles, poderemos abrir um novo canal de entendimento (intercompreensão) e afirmação das identidades sociais e pessoais.

O Ponto de Cultura pode ser (ao menos este é o desejo) um ponto de apoio a romper com a fragmentação 
da vida contemporânea, construindo uma identidade coletiva na diversidade e na interligação entre diferentes modos culturais. Quem sabe, um elo na "ação comunicativa", como na teoria de Jürgen Habermas.

A equação em que se sustenta a teoria dos Pontos de Cultura foi construída a partir da observação empírica, com casos vivenciados. E pode ser expressa em uma equação simples, em que a soma de autonomia + protagonismo resulta em um contexto favorável ao rompimento de relações de dependência, ou assistencialismo, tão comuns na aplicação de políticas governamentais.

Esse novo contexto representa um avanço em política pública e pode ser potencializado se, ao resultado daquela soma, agregarmos a articulação em rede. Quanto mais articulações e redes houver, mais sustentável será o processo de empoderamento social desencadeado pelo Ponto de Cultura. Com essa equação, percebe-se que um Ponto de Cultura só se realiza plenamente quando articulado em rede.

\section{Rede das Casas de Cultura em Campinas: a evolução do conceito.}

\section{Marquesa. Empregada doméstica que carrega no primeiro} nome um título de nobreza. E eram nobres seus propósitos. Moradora de um bairro distante do centro de Campinas, o Parque Itajaí, reuniu um grupo de mães e procurou a biblioteca pública com a seguinte proposta:

- Queremos um curso para aprender a orientar o uso dos livros por nossos filhos. E queremos livros, também, pois a biblioteca mais próxima fica a 20 quilômetros de nossas casas.

TC. Apelido de Antonio Carlos Santos da Silva, um Silva entre milhões. Nos anos 1970, fez supletivo e teatro popular no Colégio Evolução, de Campinas. Músico e militante do movimento negro, nunca esperou pelo que pudesse receber de fora. Compunha suas canções, fazia cartazes em serigrafia, andava (e continua andando) pelas periferias e interior do Brasil, tecendo uma rede de mocambos e plantando mudas de baobá, a árvore africana da memória, que no tempo da escravidão tornouse a árvore do esquecimento.

Na mesma época em que Marquesa procurou a biblioteca (1990), TC buscou apoio para transformar em Casa de Cultura parte de um armazém desativado da Companhia Brasileira de Alimentos - Cobal, igualmente em um bairro popular de Campinas, a Vila Castelo Branco.
Assim começou a rede de 13 Casas de Cultura na cidade. Concebida como espaço comunitário, cada Casa recebia: uma pequena biblioteca com 500 livros, treinamento para orientadoras de leitura, um agente comunitário (selecionado na própria comunidade e recebendo um salário mínimo por mês), oficinas artísticas, ingressos gratuitos para espetáculos nos dois teatros municipais e apoio para eventos locais ou integradores de rede, como o Recreio nas Férias.

Uma ação simples, nada grandiosa, calcada na realidade e na generosidade de nosso povo. "A solução dos problemas do Brasil virá da escassez... e dos de baixo", lembra Milton Santos nos seus últimos escritos, deixados como herança ao povo do Brasil.

A maioria das Casas de Cultura nasceu em projetos adaptados, por vezes uma associação de moradores ou casa-protótipo em vilas de Cohab, dessas que as pessoas visitam para planejar como serão suas próprias casas depois de prontas, com sala, pequena cozinha, um banheiro e dois quartos.

Das treze Casas da Cultura, apenas duas dispunham de um pouco mais de estrutura física, com auditório, cinema ou teatro. Mas essa falta não impedia que fossem realizados espetáculos ou montagens mais complexos. A Casa funcionava como espaço de articulação que buscava outros recursos locais, como o pátio de uma escola, o auditório comunitário ou o salão paroquial. Um programa de baixo custo unitário e grande escala de atendimento, que aproveitava estruturas já existentes e era compartilhado com a sociedade.

Eu era secretário de Cultura de Campinas, na época (1990-92). A princípio, imaginava que o processo seria irreversível e nada impediria a continuidade das Casas de Cultura, nem mesmo a mudança na gestão municipal. Não foi o que ocorreu. Com a troca de governo, houve atraso no pagamento dos agentes comunitários, assim como a desvalorização das iniciativas locais e a desarticulação do Conselho de Gestores.

Esse processo de desqualificação levou à perda de protagonismo e, com o tempo, oficinas e cursos culturais foram cortados e a programação ficou irregular e desvinculada das aspirações locais. Os agentes culturais da comunidade foram se desestimulando e as Casas de Cultura deixaram de funcionar regularmente, perdendo público e referências. Perdendo vida. Dentre elas, a casa-protótipo que a população do Itajaí havia transformado em Casa de Cultura, o nobre espaço criado por Marquesa. 
O Ponto de Cultura Tainã, em Campinas, como o pássaro que lhe empresta o nome, ganhou asas e voou. Esse voo livre foi decorrente de sua autonomia. Mas como se chegou a ela?

\author{
Num encanto, a natureza aflora \\ e o povo vai embora, que é hora de trabalhar \\ E assim o nosso dia se transforma na agonia de estar vivo sem \\ poder viver \\ E o que será do amanhã se a gente não lutar pelo nosso direito \\ de ser? \\ Ser livre e ser feliz.
}

Samba-enredo composto por Antonio Carlos Santos da Silva, o TC, em parceria com Aloísio Jeremias, em 1983.

Tainã, um pássaro. Esse era o nome da Casa de Cultura fundada por TC. Como estava habituado à escassez, seguiu com seu povo, independente do apoio da prefeitura de Campinas. A Casa continuou aberta com programação vibrante, oficina de tambores, serigrafia, iniciação musical, biblioteca, horta, forno comunitário (a refeição é uma forma de cultura); depois, telecentro e até orquestra de tambores em metal (steal drum), com melodia surpreendente. E os moradores do bairro continuaram tecendo o seu Ponto.

Em 2005, a Tainã torna-se Ponto de Cultura reconhecido pelo governo federal e, em 2006, recebe a Ordem do Mérito Cultural pelas mãos do presidente Lula.

Evidentemente, os gestores das outras Casas também estavam habituados a conviver com a escassez e são gente valente e lutadora. Mas o que fez a Tainã sobreviver com mais força e avançar mais que as outras?

- Autonomia.

Autonomia não como uma simples transferência de responsabilidades que antes caberiam ao Estado, ou um fazer por conta própria, desarticulado de seu meio e sem clareza de pressupostos conceituais e éticos. Autonomia enquanto capacidade de tomada de decisão e sua implementação conforme os recursos disponíveis.

Autonomia na experiência, na articulação em rede, obtida no processo de aquisição do conhecimento, na relação entre os pares e na interação com autoridades, sejam mestres da tradição oral ou autoridades institucionais.

Autonomia como prática, como a própria realização, com atos concretos de participação e afirmação social; protagonista, articulada em rede, modificando relações de poder e gerando empoderamento social. Autonomia como exercício de liberdade.

De repente me dou conta do caráter espinosiano do filósofo Espinosa - contido na música deles: a liberdade como exercício da felicidade.

Antes de o pássaro Tainã levantar voo, já estava expresso o protagonismo daqueles que formariam o Ponto de Cultura. 0 protagonismo dos movimentos sociais aparece na medida em que seus integrantes e suas organizações se entendem como sujeitos de suas práticas. Sujeitos que intervêm em sua realidade, desde os hábitos cotidianos até a elaboração de políticas de desenvolvimento local.

Entretanto, gestões públicas de cultura pensadas nos marcos do (neo)liberalismo ("cultura é um bom negócio!") ou do lluminismo (“levar luzes à inculta massa”) retiram da sociedade as suas ferramentas mais preciosas: sua autonomia e seu protagonismo. Se a cultura for pensada somente como produto, sinônimo de modernização ou negócio, o povo fica fora do palco.

Quando as políticas de Estado não reconhecem a criação cultural das paneleiras de Goiabeiras, em Vitória, no Espírito Santo, ou do mestre de brinquedos do Vale do Jequitinhonha, privando-os de seu protagonismo, tratando-os como folclore ou expressão de uma cultura ingênua, "simples”, estabelece-se uma quebra na relação (que deveria ser) de igualdade entre sistema dominante e sociedade.

Esse não reconhecimento tem por matriz um conceito de cultura vinculado ao de civilização. Cultura é aí pensada como o meio pelo qual se mede o desenvolvimento e o progresso, a modernização e refinamento da nação. Os "simples" precisam ser colocados em seu "devido lugar": uma peça de museu, um artesanato ingê- 
nuo, uma massa a ser formatada. E o sistema se mantém dominante.

Dessas concepções, nasce o "dirigismo" nas gestões públicas de cultura. À medida que são criados parâmetros de reconhecimento e validade para algumas manifestações culturais, e não para outras, o patrimônio cultural da sociedade vai ficando incompleto, apartando a imensa maioria do pleno exercício de sua cidadania (ou do palco).

Negar o protagonismo a essa maioria e apresentar a elite (qualquer elite) como única detentora de saber e bom gosto é um eficiente modo de assegurar a sobrevivência de formas de dominação e legitimação de classe. Aos "outros", aos "simples", é oferecida uma cultura pasteurizada, feita para atender às necessidades e aos gostos medianos de um público que não deve questionar o que consome.

A articulação em rede e o protagonismo se fazem essenciais no processo de construção da autonomia dos Pontos de Cultura. Por isso, a Tainã sobreviveu e, em seu voo, se encontra com outros Pontos, ou pássaros, que, ao voar, afirmam: "Aqui se faz cultura”.

\section{A liberdade de experimentação e o protagonismo da juventude fazem a diferença}

\section{O empoderamento social nos Pontos de Cultura pode}

provocar transformações que vão muito além da cultura em um sentido estrito e desencadear mudanças nos campos social, econômico, de poder e valores. Ao concentrar sua atuação nos grupos historicamente alijados das políticas públicas (seja por recorte socioeconômico ou no campo da pesquisa e experimentação estética), o Ponto de Cultura potencializa iniciativas já em andamento, criando condições para um desenvolvimento alternativo e autônomo, a fim de garantir sustentabilidade na produção da cultura. É a cultura entendida como processo e não mais como produto.

Em Nova Olinda, uma cidadezinha do Araripe/Cariri, a experiência de empoderamento social antecede o Ponto de Cultura. No final do século XX, um músico, filho da cidade, Alemberg, decide retornar de Fortaleza, a capital do Ceará. Sua referência: a Casa Grande, uma herança de família que estava em ruínas. Diz a lenda que era uma casa mal assombrada. Ele decide reconstruí-la e, para isso, recebe a ajuda de jovens, crianças, mulheres e velhos, pois os homens adultos, em sua maioria, haviam saído da ci- dade para buscar emprego em outros cantos.

Casa reconstruída, começam a montar um museu de arqueologia. No Vale do Araripe, além de fósseis de dinossauros, há muita pintura rupestre. A pré-história foi relacionada com a vida dos moradores, orientando-os na preservação. Surgiu a ideia de deixar que as crianças escrevessem as legendas para que a exposição ficasse inteligível para todos. Foi o que fizeram.

Mas a Casa era muito grande e havia espaço para mais atividades. E as necessidades eram maiores ainda.

Os jovens queriam produzir música; foi montada uma banda - uma não, algumas. Faltava cinema, montaram uma videoteca. Faltavam livros, criaram uma biblioteca. Faltava teatro, construíram um teatro.

Tudo muito simples e utilizando apenas os recursos de que dispunham, mas feito com muito esmero (como na música de Vinícius) e com tudo que um bom centro cultural precisa: palco com cenotecnia, refletores, mesa de som e amplificadores de qualidade, bancos na plateia, área de contemplação, foyer.

Dispondo de um museu próximo de casa, teatro, bandas de música, filmes de qualidade e livros que dificilmente chegariam ao Vale, os moradores quiseram mais: emissora de rádio, internet, TV local.

Algum desavisado que sintonizar a rádio Casa Grande vai se surpreender com programas musicais de alta qualidade: música africana, aboios (cantoria dos vaqueiros enquanto conduzem o gado: "ê boi, ê meu boizinho surubim..."), jazz, entrevistas, MPB... Tudo programado, narrado e preparado por crianças e jovens.

Quem fica por alguns dias, além de visitar cachoeiras e grutas com inscrições rupestres, ou andar a cavalo acompanhando uma boiada, à noite pode assistir a um filme do neorrealismo italiano, do Dogma dinamarquês ou do novo cinema nordestino. É só pegar um filme na videoteca da Casa Grande.

Ou ver um programa de TV local, igualmente concebido, produzido, dirigido e gerido por jovens e crianças. No início, a emissora tinha sinal aberto, mas foi fechado por não ter concessão; alegaram que o sinal atrapalharia o voo de aviões que até hoje os meninos tentam avistar nos céus do vale dos dinossauros voadores.

Com a interrupção do sinal aberto, a TV ganhou outro nome: os Sem Canal, em alusão a um famoso cinejornal dos anos 60 e 70, o Canal Cem. A cada semana, um novo programa é exibido no teatro do Ponto de Cultura. Os adultos ficam na plateia e só aparecem como entre- 
vistados, pois argumento, roteiro, direção e atuação são todos de crianças e jovens.

Também há bandinha de crianças, que tocam instrumentos inventados por eles, de brinquedo, em que a sonoridade é feita com a boca ou o batuque em latas, panelas e baldes de plástico. Quando as crianças crescem um pouco, formam suas próprias bandas, com instrumentos musicais de verdade (os instrumentos de brinquedo e os batuques nos baldes também são instrumentos musicais? São. Quer dizer que também são de verdade).

Os jovens que começaram com a primeira bandinha de brinquedo e que têm perto de 20 anos formaram uma banda de jazz experimental, misturando aboios com rock, MPB, xote e baião. Pelo Ponto de Cultura, já se apresentaram na Alemanha, no Popkomm 2006. Alguns começam a sair da cidade, não mais para buscar emprego, mas para estudar em universidades, fazendo música, teatro, antropologia, arquitetura, cinema e engenharia. Suas cabeças ganham o mundo, mas seus pés estão fincados na Chapada do Araripe.

Um empoderamento radical, desses que só acontecem de fato quando cultivados com autonomia, semeados pelo protagonismo - no caso de Nova Olinda, basicamente de jovens. Alemberg e sua esposa Rosane, arqueóloga, nem moram mais na cidade (se bem que sempre estão por perto), e o Ponto de Cultura da Casa Grande está cada vez mais forte.

Quem dirige o Ponto são crianças e jovens: um coordena a editora, outro é gerente do parquinho, outros são coordenadores de programas de rádio ou TV e alguém cuida do orçamento participativo da Casa Grande. O orçamento é exposto em mural público e apresenta desde as mais ínfimas entradas de recursos - a venda de um pedaço de bolo - até as despesas mais singelas. Cada atividade tem seu responsável e eles fazem rodízio entre si. São jovens que cresceram na Casa Grande, que aprenderam na prática e resolveram permanecer em seu vale, rompendo com o ciclo de êxodo que a todos levava.

Com o tempo, visitantes foram atraídos pela notícia que ganhou o mundo: um turismo diferente, de quem quer mudar seu olhar integrando-se ao local. Três mil visitantes por mês, em busca de cachoeiras, pinturas rupestres, ouvindo aboios, presenciando a cultura do sertão e a radical experiência de protagonismo juvenil da Casa Grande.

Com o Ponto, uma nova economia surge em Nova Olinda, solidária e sustentável. Como era preciso hospedar turistas, criaram-se hospedarias familiares e uma simples e confortável suíte no quintal da casa dos pais (principalmente das mães) dos meninos e meninas do Ponto de Cultura. 0 artesanato de couro revigorou-se com a arte de mestre Expedito e muitos outros mestres e aprendizes que agora encontram mercado para suas bolsas, sandálias e adereços.

Um consistente programa de turismo cultural com base comunitária gera nova fonte de renda para as famílias. E os adultos começam a voltar. Mais renda na cidade, e bem repartida, porque dividida entre muita gente.

A Casa Grande, antes mal assombrada, fez com que os moradores gostassem mais de si e de sua cidade, encontrando o seu lugar no mundo, cujo centro estava ali mesmo.

\section{Cultura emancipatória: é preciso juntar autonomia, protagonismo e empoderamento.}

\section{Autonomia, protagonismo e empoderamento são os} pilares da gestão compartilhada e transformadora nos Pontos de Cultura e resultam da observação de situações reais. $E$, de certa forma, da frustração com a desmobilização das Casas de Cultura em Campinas.

Qual a base real para o surgimento das Casas de Cultura em Campinas?

Se eram tão necessárias e se espraiaram com tanta rapidez, por que se esvaíram com tanta facilidade?

$\mathrm{O}$ que faltou?

0 que fez com que a Tainã tivesse outro destino?

Por que a experiência da Casa Grande é tão marcante?

As Casas de Cultura de Campinas partiram de necessidades concretas: um grupo de mães desejando oferecer atividades culturais regulares para seus filhos, artistas em busca de aprimoramento, comunidades procurando qualificar o seu ambiente. Mas será que houve enraizamento real?

Talvez tenham sido implementadas mais como resultado do meu desejo e da minha vontade de grupos isolados, tendo havido confusão entre demanda legítima de pequenos grupos com aspiração de toda uma comunidade. Seguramente faltou tempo para maturação - menos de dois anos de gestão.

A diferença entre a Tainã e o Parque Itajaí é que aquela estava mais enraizada em sua comunidade e a Casa de Cultura do Itajaí foi instalada praticamente ao mesmo tempo em que o bairro se constituía, quando os vizinhos mal se conheciam. 
O que chama a atenção na experiência da Casa Grande é a contínua busca da experimentação, o compartiIhamento das responsabilidades, a pureza com que inventam soluções, o não ter medo do ridículo e do erro, a confiança que eles têm em si mesmos; ao mesmo tempo, se mantêm acesos a curiosidade e o interesse em aprender com o outro.

Dar ênfase a apenas uma das noções seria equívoco. Autonomia e protagonismo se completam quando formam um triângulo com o empoderamento. Compõem o tripé da sustentabilidade cultural nas comunidades. Esses três fundamentos não podem ser entendidos de maneira estática ou como modelos. Por serem valores em construção, seus significados ganham relevância à medida que se cruzam e expressam as próprias experiências da cultura e dos Pontos. São valores que geram um novo conceito: o Ponto de Cultura.

Esse é um caminho diferente de inclusão e sustentabilidade social, e envolve não somente a capacitação a partir da vocação cultural de cada grupo, como também um processo de inclusão social, digital, cultural, econômica e política.

A integração dessas noções e conceitos dá início a um novo processo de cultura política com caráter emancipador, em que o Ponto de Cultura quebra hierarquias sociais e políticas e cria bases para a construção de novas legitimidades.

\section{0 entrelaçamento de sujeitos}

É recorrente a divisão dos movimentos sociais, organizada por estudiosos e especialistas, entre duas categorias distintas. Os movimentos sociais definidos como "tradicionais" abarcam os sindicatos, associações de moradores, entidades estudantis. Esses movimentos se expressam a partir de sistemas de poder hierarquizado em graus e escalões, atribuições de postos, fluxos de relacionamento preestabelecidos, definição rígida de papéis, com segmentação setorial e competitividade interna.

Esse modelo de organização social sofreu sério desgaste a partir do final do século XX e tem encontrado muita dificuldade em responder às demandas dos próprios setores que pretendem representar.

Em outro modelo, são identificados os chamados "novos" movimentos sociais, cuja referência pode ser encontrada no movimento hip-hop, ambientalismo, cooperativas e rádios comunitárias, nos movimentos de ca- ráter identitário, como de mulheres, negros, homossexuais. Há também as ONGs, com foco temático, territorial ou de público.

Apesar de estarem enquadrados em uma mesma categoria, esses movimentos têm origens sociais as mais diversas: uns nasceram na periferia das grandes cidades, em busca de conexões de solidariedade entre os excluídos de bens e direitos; outros nascem na classe média, em busca de conexões de identidade setorial e defesa de causas. Ainda que devam ser vistos como movimentos heterogêneos e que congregam sujeitos sociais bastante diferentes, as organizações não governamentais tornaram-se referência importante para a construção de novas relações entre estado e sociedade.

Já outra parcela das organizações sociais, que tem sido, inclusive, a que responde de forma mais original e imediata aos convites do Cultura Viva, são as comunidades tradicionais e a iniciativas não propriamente de caráter reivindicativo; podem ser definidas como grupos culturais, organizações de comunidades quilombolas, indígenas, de ritmos e danças tradicionais e populares, como escolas de samba, maracatus, cirandas, quadrilhas, capoeiras, ou manifestações de caráter cultural/religioso.

Esse "estar à margem" imunizou suas organizações dos dilemas dos movimentos sociais tradicionais (com caráter reivindicativo ou representativo) e dos "novos" movimentos sociais (com caráter temático e fragmentado), preservando sua fluidez e agilidade. No entanto, "guetizou-os", apartando-os de um movimento por mudanças em um sentido mais largo.

Sem um diálogo com a nova realidade, muitos desses movimentos não se renovaram e permanecem escondidos e ensimesmados, ou foram absorvidos pelo mercado ou pela cooptação política, como no caso das escolas de samba das grandes cidades. Convenientemente classificados na categoria do "folclore" - na irônica definição de Roger Bastide, "cultura em conserva" -, restam e permanecem inacessíveis e incompreensíveis a outros setores sociais.

Se, por um lado, apresentam estruturas aparentemente rígidas e hierarquizadas (o "dono do boi”, por exemplo), por outro, há muito de leveza e descomplicação em suas formas organizativas, o que faz com que convivam constantemente com a dialética tradição-invenção que caracteriza suas ações.

Esses movimentos foram criando formas subterrâneas 
de direito político antes mesmo que a sociedade civil ou a cidadania moderna se estabelecessem entre nós. Tomaram as ruas e canaviais nos momentos de festa, afirmaram identidades e exercitaram o compartilhar.

Quem acompanha uma Folia de Reis percebe que ela é puro resultado do compartilhamento. Alguém cede adereços, tecidos; outros costuram roupas; em cada casa visitada, há um prato de comida, por vezes colocado na janela para ser sorrateiramente roubado, como parte da brincadeira. Assim, os participantes da Folia de Reis sobrevivem por dias; e a cultura popular sobrevive por séculos.

Comumente excluídos das políticas públicas, com o Ponto de Cultura as expressões tradicionais se afirmam como sujeitos relevantes na forma de fazer política.

O programa Cultura Viva aproxima esses diversos movimentos, aqui classificados em três:

a. associativos/reinvindicativos;

b. novos movimentos sociais;

c. manifestações culturais e tradicionais.

Essa aproximação não ocorre para que um campo hegemonize outro, ou para uniformizar formas de expressão e organização, e sim para que se conheçam e se exercitem na tolerância, autoeducando-se no convívio em rede.

Quando os todo-poderosos governam com a irrazão e sem limites, só os que possuem nenhum poder são capazes de imaginar uma humanidade que um dia terá poder e, com isto, mudará o próprio significado desta palavra.

Terry Eagleton

A Ideologia da Estética

O entrelaçamento de sujeitos sociais e o seu desenvolvimento com autonomia, protagonismo e empoderamento se completam. A agenda de estímulos do Programa Cultura Viva pode gerar uma nova forma de fazer política pública e de cultura política. Essa concepção cria possibilidades de construções coletivas, feitas no processo de seu desenvolvimento. Diferente dos velhos caminhos que, mesmo quando se apresentam como novos, estão previamente definidos nas cartilhas de gestão, planejamento e gerência para a administração pública, o Cultura Viva não apresenta receitas a serem seguidas; ao estimular e potencializar as energias sociais e culturais já existentes, valoriza a experiência social.

A gestão compartilhada e transformadora se realiza nesse processo de aproximação e compartilhamento de responsabilidades entre estado e sociedade, no qual gestores públicos e movimentos sociais estabelecem canais de diálogo e aprendizado mútuos.

Esse é um caminho que repensa o Estado e amplia suas definições e funções ao escancarar as portas para partilhar poder e conhecimento com tradicionais e novos sujeitos sociais, dividindo espaços e buscando novas possibilidades.

\section{Afinando o conceito: entrelaçar as diversas dimensões da vida.}

\section{A expressão Ponto de Cultura foi utilizada pela primeira} vez no final da década de 1980, quando o secretário de cultura em Campinas era o antropólogo Antonio Augusto Arantes.

Alguns anos depois fui nomeado secretário de cultura. Com Marquesa, Ana Mattos, TC, Tom Crivelaro, Marcos Brito e tantos outros, a rede deslanchou. Por equívoco das tentações 'marqueteiras' da política, o programa levou o nome de Casa de Cultura, pois a expressão Ponto de Cultura poderia ser associada ao governo anterior. Quis o destino que eu pudesse aprender com os erros, aprofundar o conceito e aplicá-lo em escala nacional; retomei, inclusive, a expressão Ponto de Cultura.

A diferença de fundo entre Ponto de Cultura e Casa de Cultura consiste em que esta, mesmo quando compartilhada com a comunidade, é resultado de uma ação governamental e mais voltada a edifícios vocacionados. É o governo que constrói ou adapta o espaço e que decide a localização e a sua programação.

No Dicionário Crítico de Política Cultural, o professor Teixeira Coelho aponta que esses espaços implicam

\footnotetext{
(...) uma desterritorializacão da cultura ou dos modos culturais: práticas inicial ou originariamente exercidas num determinado lugar passam a sê-lo num outro lugar com o qual não estão histórica ou socialmente ligadas. Esse artificialismo de origem é tão evidente e acentuado que não raro surge como motivo principal da decadência ou não utilização plena de seus recursos e possibilidades.
}

Com o Ponto de Cultura, o processo é inverso, cabendo ao governo reconhecer e potencializar as iniciativas culturais da comunidade no território em que elas acontecem. Fazer cultural e território estão intrinsecamente vinculados. 
Outra dúvida recorrente é sobre o fato de o Ponto de Cultura substituir a necessidade de outros equipamentos culturais. Pelo contrário, o Ponto de Cultura cria condições favoráveis para a consolidação de uma base social da cultura, assegurando meios mais perenes para a conquista de melhores bibliotecas, teatros bem equipados, centros culturais dinâmicos, museus vivos e políticas de fomento à formação, produção e difusão cultural.

Entender a cultura como processo pressupõe entrelaçar as diversas dimensões da vida. Com a posse do ministro Gilberto Gil, o ministério adotou um conceito ampliado de cultura, antropológico: cultura como produção simbólica, cidadania e economia.

A dimensão da arte não pode ficar restrita ao campo do simbólico. Para além da produção de símbolos, a arte envolve habilidades, todas as habilidades humanas (do latim artem, habilidade) e a apreensão dos significados por meio dos sentidos, de uma percepção sensorial.

O Ponto de Cultura envolve uma quebra nas narrativas tradicionais, monopolizadas por poucos, e a partilha do sensível é estratégica para este deslocamento narrativo, em que os "invisíveis" passam a ser vistos e a ter voz. Não se trata aqui da defesa do "belo universal" ou da "arte gratuita”, metafísica, e sim da própria realização da estética.

A arte reflete aspirações e contradições do seu contexto histórico e é, ao mesmo tempo, produto e vetor das transformações sociais. Para além da preocupação exclusiva com a beleza, busca-se tudo aquilo que permita a afirmação cultural da subjetividade das pessoas, grupos e classes sociais. E essa busca deve ser feita com encantamento, beleza e qualidade, pois sem esses atributos não se rompem barreiras e os estereótipos permanecem.

O mesmo ocorre com a dimensão cidadã. A conquista plena de direitos e a inclusão no diálogo cultural são essenciais; mas circunscrever Ponto de Cultura à dimensão de cidadania ou da cultura popular é uma redução.

Mais grave ainda são os discursos fáceis da "inclusão cultural" ou da "inclusão social por meio da cultura". Ponto de Cultura atua com cultura popular, inclusão social, e tem um claro papel na cidadania, mas ele é, sobretudo, um programa de cultura. Cultura como interpretação do mundo, expressão de valores e sentimentos. Cultura como intercompreensão e aproximação. Nesse sentido, seria mais apropriado classificar a ação do Ponto de Cultura no campo da ética.
Com a economia também é preciso aprofundar o conceito. Que economia queremos? De um lado, é fato que exista a economia da cultura (pesquisa do IBGE aponta que $8 \%$ do PIB advém da cultura). Mas em que contexto se insere a chamada "economia criativa"? O capitalismo se apropria de todas as riquezas e bens produzidos sobre a face da Terra (e também sob; e, no futuro, se puder, para além do planeta) e os transforma em mercadoria, sejam bens sólidos ou imateriais.

Inserir a cultura nesse processo de mercantilização e alienação da vida não é o objetivo do Ponto de Cultura. Em Pontos isolados, em que falta discussão, isso até acontece; ou, se não acontece, se deseja (até porque os que querem se vender nem sempre encontram compradores).

0 entendimento que está sendo construído no processo é que, se a economia determina a cultura, a cultura também determina a economia. Ao adotar uma nova atitude cultural, podemos modificar as relações econômicas, abrindo caminho para uma economia solidária, com consumo consciente, comércio justo e trabalho colaborativo.

Vejo a fagulha dessas novas relações econômicas, sobretudo na Teia, com o encontro dos Pontos de Cultura com os Núcleos de Economia Solidária do Ministério do Trabalho.

Ponto de Cultura é integração na diversidade. "A parte está no todo, o todo está na parte”; a física quântica comprova esse conhecimento milenar, que foi abandonado pela fragmentação da vida. Passados cinco anos de implantação dos Pontos de Cultura, observo que a reaproximação entre estética, ética e economia é essencial para a organização da vida humana e pode cimentar uma nova significação para a cultura e para a própria sociedade. Não há como separar um do outro, os três "Es" da cultura: ética, estética e economia.

\section{Nota}

1 A íntegra deste texto está publicada no livro: Turino, CÉLIO. Ponto de cultura: o Brasil de baixo para cima. São Paulo: Anita Garibaldi, 2009.

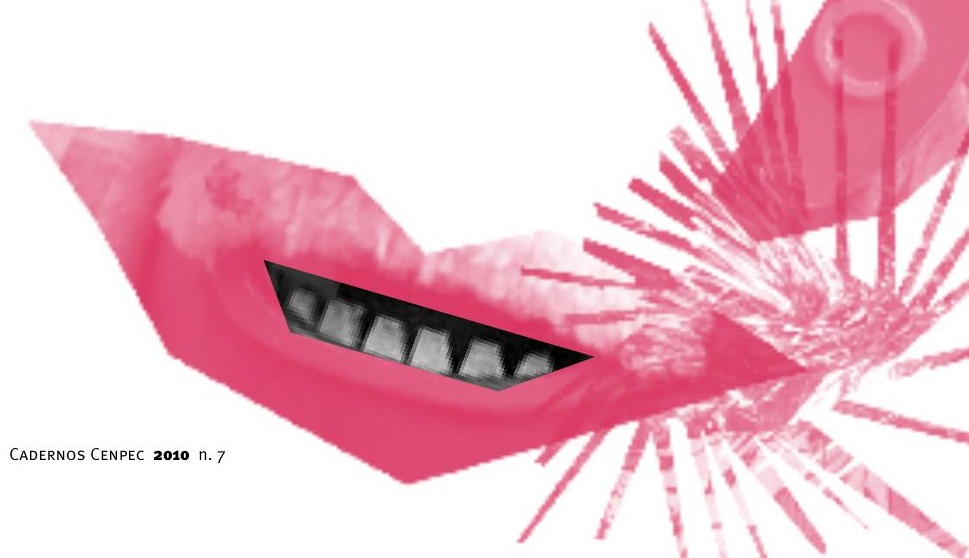

